\title{
LEARNER ENGAGEMENT IN COMMUNITY HEALTH AND DEVELOPMENT: ISLANDS, ISOLATION AND IMPACT
}

\author{
Cynthia Mullens and Michael Mullens
}

\section{INTRODUCTION}

This report sets out the ways in which personal connections and volunteer work guided our research focus on community health and development and our engagement in work-based learning through the Doctorate of Professional Practice Framework.

Having both worked extensively in relief and development, the authors took the opportunity to join a group of dedicated individuals to travel to the island of Paama, Vanuatu, at the beginning of 20 I8. A long-term connection dating back to 2001 between community elders from the village of Liro and volunteers from Dunedin, New Zealand, meant that much of the hard work of developing trust and establishing relationships had already been done. (Figure I shows the situation of the remote island of Paama within the archipelago of Vanuatu.)

The Paama community extended an invitation to the authors to establish outreach opportunities for Otago Polytechnic learners from Dunedin. Working within the School of Engineering and the School of Nursing at Otago Polytechnic, Dunedin, the authors set out to develop and provide problem-based, real-world learning in regards to water, sanitation and health. This report details the initial work undertaken on a ten-day field trip in September 2018.

Historically, access to clean drinking water has determined health outcomes in many parts of the world. With changing climate and accessibility to water, as well as contamination of water sources, the World Health Organisation (WHO) estimates that by 2025 half of the world's population will be living in water-

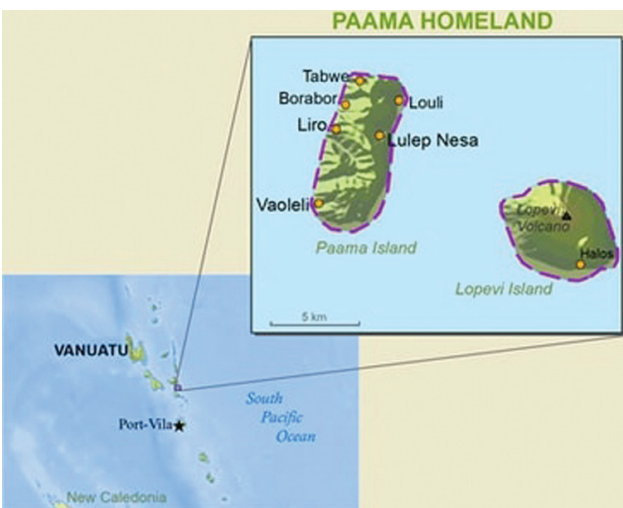

Figure I. Map of Paama, Vanuatu. Source: http://pacificpathways.org.nz. stressed areas $(\mathrm{WHO}, 2019)$. It has been estimated that close to 785 million people lack basic drinking water services, and over 144 million people are dependent on surface water for drinking (WHO, 2019). Globally, two billion people are utilising a water source contaminated with faeces, contributing to the transmission of diseases including diarrhoea, cholera, dysentery, typhoid and polio (WHO, 2019).

Effective and safe water systems are imperative for the promotion of health, the prevention of disease and the understanding of disease management within communities. 


\section{CONTEXT}

Historically known as the New Hebrides, the archipelago of Vanuatu gained independence from French and British colonisers on 30 July 1980. In general terms, the separate focus of competing British and French administrations has contributed significantly to the post-independence unrest experienced by Vanuatu since joining the Commonwealth in 1980. Political controversy and foreign investment continue to undermine the capability of communities to establish operational systems that effectively manage health and wellbeing. The majority of services are developed and managed from urban areas, leaving smaller islands at the mercy of climate change, migration problems and economic disadvantage on a much larger scale than their urban counterparts are experiencing.

The definitions of "rural" and "remote" as they apply to the areas of health and wellbeing often equate to isolation in regard to place and the culture of "self-sufficiency" (Howie, 2008). Complicating the definition of rurality are the lenses through which various disciplines and professions view this concept. Dillon (2008) linked the concept of rurality with that of "islandness" in her exploration of what constitutes a rural context. Similarities between the two include:

I. The impact of climate and the seasons as they relate to sustainable economic viability

2. The migration of populations seeking resources outside a particular locality

Economic factors known as "diseconomies of scale:" a financial drawback or cost arising from a particular process for example, the cost of transport or access to services - which can disadvantage individuals. Services are generally designed, implemented and regulated with larger geographical areas such as urban regions in mind, and local focus and autonomy is often disregarded in favour of systematic process.

Delivery of and access to care is determined by the structural design of the appropriate systems, as well as considerations of how rural isolation can affect health. These conditions and challenges affect island populations in a particular way, meaning that the island of Paama faces many of the same challenges as rural communities in New Zealand. However, the island's unique socio-political history and geographical location require further discussion when considering issues of work and community development.

The island of Paama is approximately $8 \mathrm{~km}$ long and $5 \mathrm{~km}$ across, and is distant from the capital of Port Vila. Paama can be visited by taking a 45-minute charter flight from the capital, landing on one of the shortest grass runways in the region, or by means of a 24-hour boat journey. (Figure 2 shows a charter flight departing Paama from the grass airstrip.) While the population of the island stood at approximately 2000 in 2019 , the movement of individuals seeking work on larger islands means that this figure is not constant, but changes with the availability of work and financial or educational demands. The traditional language spoken in Paama is known as Voum. However, the majority of residents speak Bislama, an English-based Creole language that combines English, French and local vocabulary.

Most of the island's income is from agriculture. Crops include yams, manioc, taro, banana, kumala (sweet potato) and "island cabbage" (bok choy), produce which which is exported to the

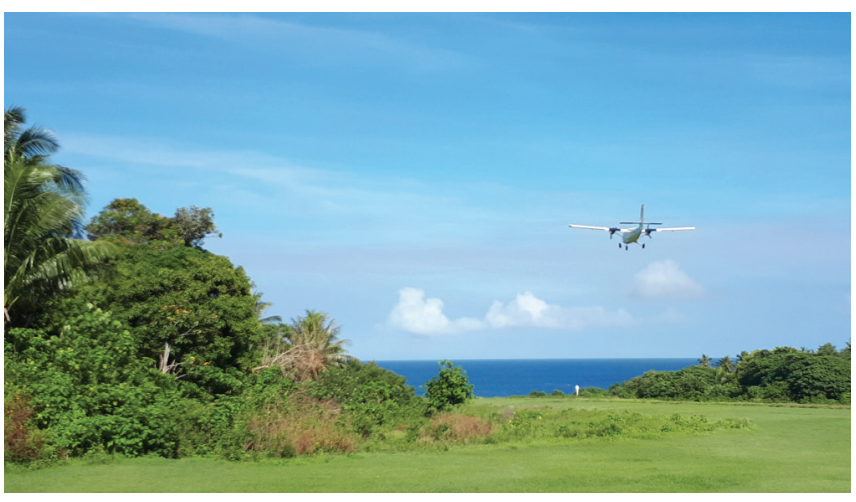

Figure 2. Charter flight leaving Paama. Source: Authors. 
larger islands. Employment on the island includes nursing, teaching and banking. Individuals make an income through activities such as selling crops in the market, dressmaking and basket and mat weaving. There are a few independent store owners as well. Many people on Paama participate in seasonal work programs in Australia and New Zealand, primarily apple- or grape-picking for six to nine months of the year. Most of these earnings are sent home to support workers' families on the island. The agricultural economy and self-supporting communities have historically been the way of life in Liro village. However, technology and increasing communication with the outside world are changing the traditional focus of many who live here, especially the youth.

In a time of global awareness and connectivity, citizens and governments in the developed world have a responsibility to assist island nations in securing access to water and sanitation. The United Nations Sustainable Development Goals speak to the fundamental need for public health and sustainable development objectives to be met by 2030 (United Nations, 20I5). Water, Sanitation and Hygiene (WASH) are often grouped together, as the impact and deficiencies of each are substantially overlapping.

Globally, many agencies are involved in developing water and sanitation infrastructure projects in island nations. However, advancing projects is never as simple as implementing a solution and then walking away. As with most projects, in this area there are multiple factors at play, which can affect the long-term outcome in regards to community development. The assumption that any water and sanitation project will have a positive impact on the health and prosperity of a community can result in suboptimal outcomes. Poorly planned or executed development projects will be ineffective, and even have a detrimental effect on the community in the long term. Such projects can be environmentally unsustainable, culturally inappropriate and create dependence on donor organisations and non-governmental organisations (NGOs). As a result, agencies must carefully consider project design and delivery in order to maximise the small window of opportunity available and minimise the risk of failure. Many well-designed projects fail due to poor maintenance of the accompanying infrastructure in the years after completion. Engagement of community and donor organisations is vital to successful outcomes.

With these factors in mind, the School of Engineering, Construction and Living Science at Otago Polytechnic, Dunedin, developed a program that would offer second-year learners an opportunity to become involved in WASH projects focused on the South Pacific region. Following the implementation of a water system, the School of Nursing at Otago Polytechnic agreed to support the health needs of the community through annual field trips over a two-year period. This arangement would allow a five-year research focus for this community. School of Nursing research by Ross, Crawley and Mahoney (2017) into the teaching and learning involved in sustainable community development, and how nursing students can make a difference to health outcomes, laid the foundation for the development of the Community Health Assessment Sustainable Education model (CHASE). Future work on this rural educational health model will investigate its transferability from rural to island populations.

\section{PURPOSE}

The objectives and aims of the overall project were to provide learners with WASH projects and opportunities to develop them in the Liro community, using their academic knowledge and skills to provide real-world solutions under challenging conditions. The testing of projects in real-world conditions, coupled with the unique challenges consistently faced by island communities, provided learners with the opportunity to apply their academic knowledge, thus linking their theory with their practice.

The purpose of this initiative was to develop water and sanitation projects that will meet the water, sanitation and health needs of communities in the South Pacific region. The development objectives were to build sustainable water and sanitation projects, increase health and educational capacity in local communities, and encourage local people to develop ongoing relationships with Otago Polytechnic. Our focus was on long-term sustainable development and on transfering knowledge and skills. 
The project offered students who had completed civil engineering courses in Water and Waste Systems (DE6205) and Water and Waste Management (DE6206) at Otago Polytechnic an opportunity to participate in the field trip. The School of Nursing provided health support for the team, as well as capacity building through the development of relationships with the Liro community. Lecturers, community elders and health-care workers collaborated and identified future outreach opportunities for nursing learners. Projects identified include a community health needs analysis and health resource development as a follow-up to the water implementation project.

\section{LOGISTICS AND FUNDING}

A ten-day field trip was scheduled in 2018 for the second semester mid-term break. A total of 14 engineering students and two lecturers, one from the School of Engineering and one from the School of Nursing, were allocated to the team. The cost of student travel was determined at $\$ 3000$ per person. This included the cost of airfares, accommodation, food and travel insurance. Otago Polytechnic supported learners by contributing $\$ 1000$ per student towards their overall costs, with the expectation that they would meet any additional costs themselves.

The team worked together over a nine-month period to cover the additional $\$ 2000$ per student required through a variety of fundraising events. Otago Polytechnic lecturers self-funded their participation, with any surplus funds donated to participating learners and supplies for the projects undertaken.

\section{PROCEDURE}

With projects on this scale, there are always challenges relating to engagement by the local community. Community involvement is essential to ensure that local people are the chief stakeholders in the project. Exploring communities' needs at the grassroots level promotes a bottom-up approach, as opposed to a top-down administration of policy and projects. Logistically, this approach is imperative for community development, empowering individuals and discouraging long-term dependence on aid.

In July 20 I , an advance team consisting of the authors and the original group of volunteers from Dunedin travelled to Vanuatu for an initial assessment of the community's needs. Collaboration with the aim of identifying viable projects involved a wide range of community members. This included the local community Peace Corps volunteer, the Liro Water Committee, a group of community elders (both men and women) and the village chief. Discussions of technologically appropriate solutions to the needs identified by the community directed the field trip made by the School of Engineering two months later, in September 2018.

\section{THE PROJECTS}

In what follows, we describe the three projects which the Liro community identified as high priority and achievable in the short time frame available.

\section{Project I -Toilet and Shower Block for Health Centre}

The village health centre provides local and regional health facilities for the population of Paama and the smaller island communities nearby. The existing building was no longer fit for purpose and has suffered a significant amount of wear and tear. Often families need to stay there to receive care or await transport via ship to Port Vila for extended periods. No shower or toilet facilities in working order were available for use by patients and families. On this basis, this was considered a viable project to initiate.

An initial assessment revealed an existing structure that would readily convert to a toilet and shower block, and serve the health centre's needs. (Figure 3 shows the existing structure which was chosen for conversion.) 
After the scope of the project had been explained, the learners developed a number of designs for the toilet and shower block, using the knowledge gained from their Water and Waste Systems course at Otago Polytechnic. The chosen design determined the materials and supplies required. Supplies were purchased in Port Vila and transported by boat in advance of the learners' arrival.

Each team involved in the project consisted of six members and included a team leader, engineering learners and a member of the local community appointed by the water committee. As the project transitioned through its various phases, other teams were mobilised to assist with the more complex issues that arose. The project was successfully completed within the ten-day time frame, and local engagement meant that knowledge of the working system would ensure ongoing maintenance of the project. (Figure 4 shows the almost completely converted structure, now comprising two shower stalls, two flush toilets and a changing area.)

\section{Project 2 - Sanitation Field}

In order to manage the effluent and wastewater from the toilet and shower block, a sanitation field was required to be designed and constructed. Learners used knowledge derived from course content to design a sanitation field to deal with the discharge. A previous assessment had located an ideal area for the sanitation field, and geo-testing had indicated the ideal soil conditions and slope required for breakdown of the effluent.

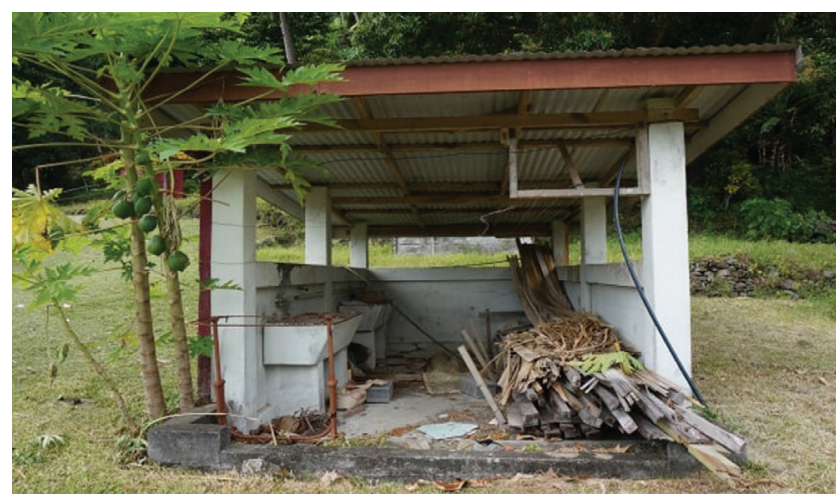

Figure 3. Existing structure chosen for conversion to a toilet and shower block. Source: Authors.

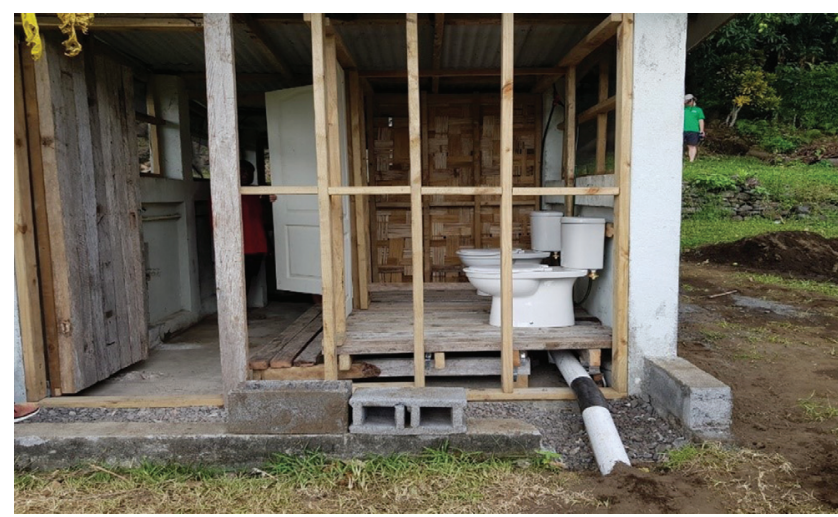

Figure 4. Shower and toilet block nearing the final stages. Source: Authors.

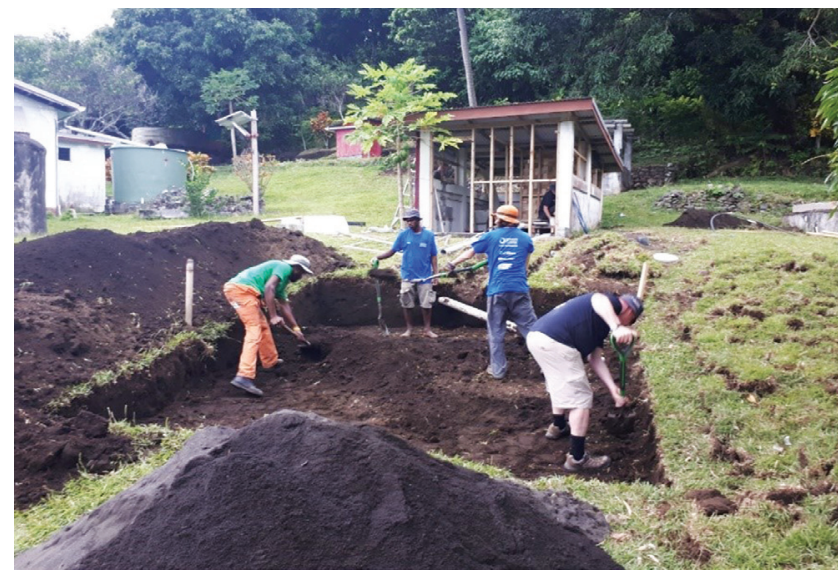

Figure 5. Construction of sanitation field for renovated toilet and shower block. Source: Authors. 
Existing polyvinyl chloride (PVC) pipes were used in the design of the manifold to ensure even distribution of the effluent over a $12 \mathrm{~m}^{2}$ area. The plan included the provision of backfill involving wire netting, sand, and compact soil and turf. This was the first time that this community had helped create and develop a working knowledge of a sanitation field, as most toilets in the village are pit latrines. (Figure 5 shows the construction of the sanitation field, with community participation.)

\section{Project 3 -Water Security}

One of the major issues facing Liro is water security, a problem exacerbated by natural disasters such as cyclones, volcanic eruptions and climate change. Water security is the most serious threat to the livelihood of this island community. Previous assessment visits had enabled the advance team to evaluate a number of possible solutions, in consultation with the Department of Water ResourcesVanuatu and the Paama Water Committee.

Possible project areas included constructing water catchment tanks, rehabilitating existing underground water tanks, developing access to local springs, increasing water storage capacity, desalinisation and the development of water management techniques at the local level.

Following community consultation, it was determined that the focus would be on establishing new water tanks, in addition to rehabilitating existing underground structures. Funding raised by the engineering learners enabled the purchase of four 10,000-litre tanks in Port Vila and their delivery via ship prior to the learners' arrival. These tanks were strategically located around the community. Collaboration between the learners and community volunteers resulted in cement bases being designed and built to support the new structures.

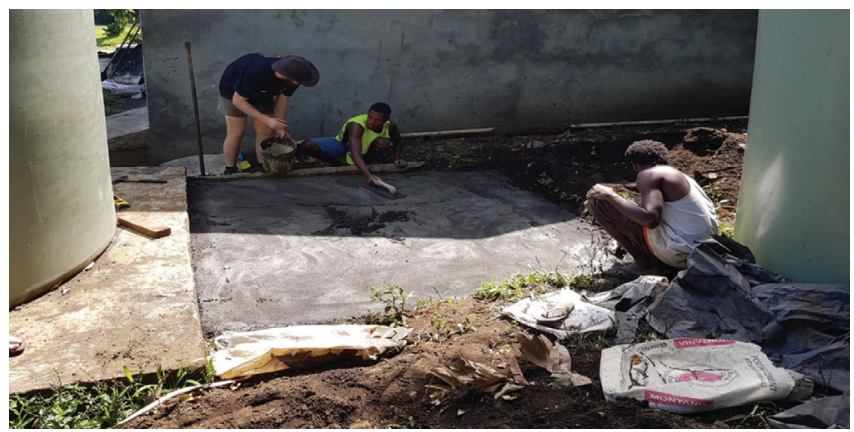

Figure 6. Cement base construction for a new community water tank. Source: Authors.

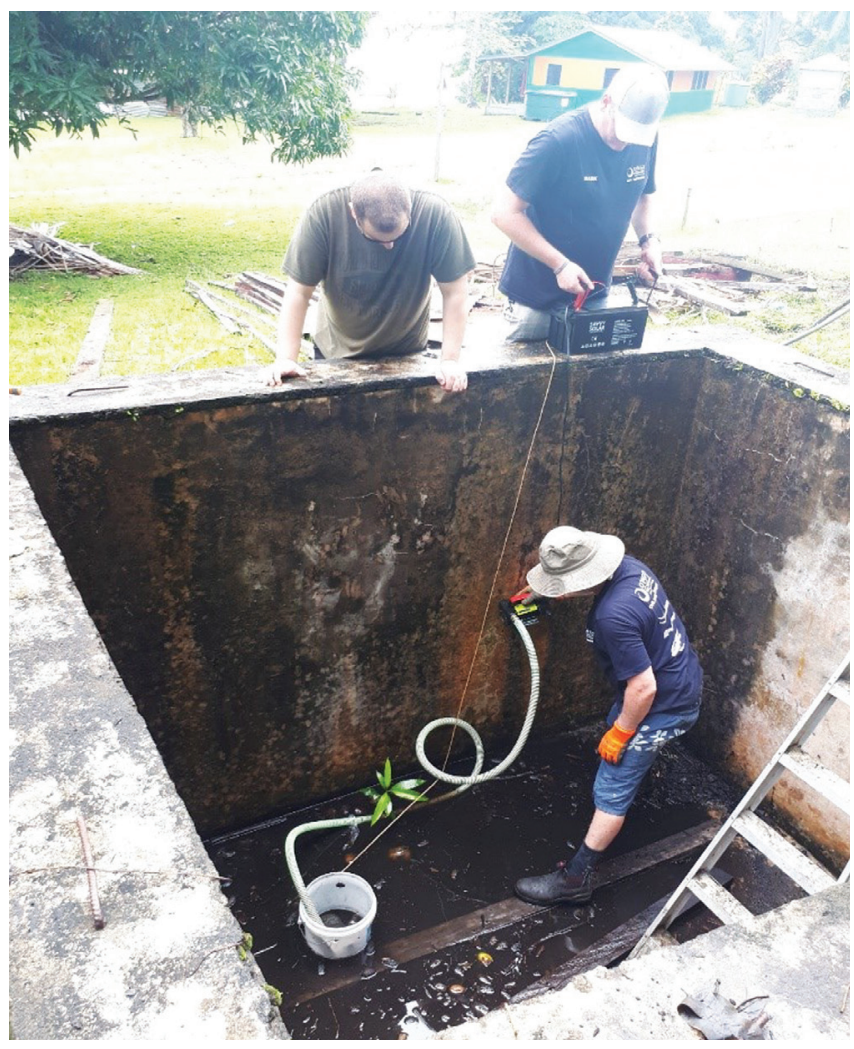

Figure 7. Rehabilitation of existing ground water tanks. Source: Authors. 
Rainwater collected from roofs using bamboo guttering and PVC piping provided greater volumes of water to supply the storage tanks. (Figure 6 shows the construction of one of the cement bases for the tanks.)

Rehabilitation of existing underground tanks meant that valuable collection facilities could be used once again to provide sources of potable water. This involved assessing the tanks for leaks, cleaning them and designing covers to keep environmental contaminants out of the water supply. (Figure 7 shows the cleaning and inspection of an existing water collection system to determine its suitability as a

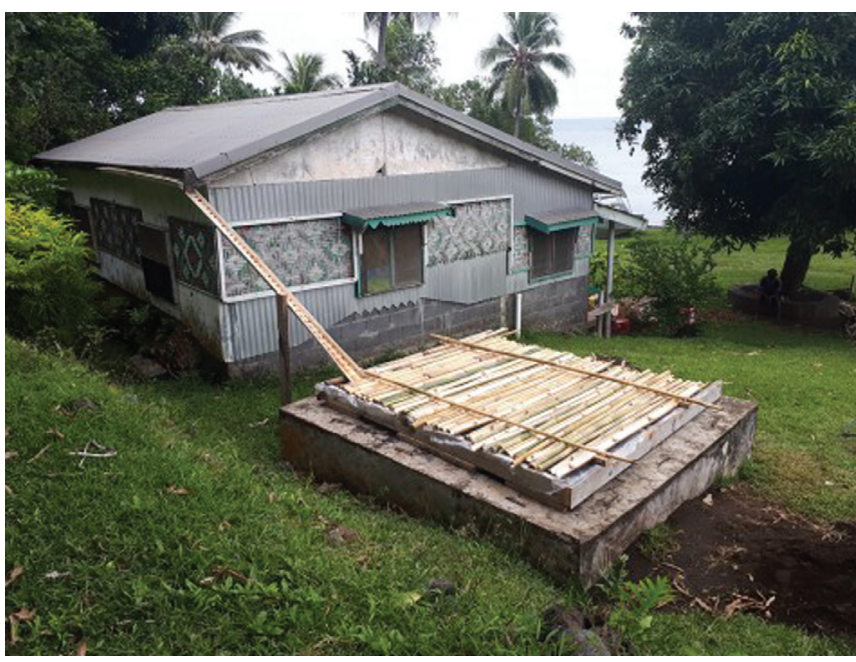

Figure 8. Bamboo covers and guttering were provided for existing underground tanks. Source: Authors.

collection and containment tank.)

Figure 8 shows a bamboo cover constructed by learners to protect the underground water collection point. Locally sourced bamboo was used as a way of ensuring that appropriate, sustainable technology, design and construction was utilised.

\section{FINDINGS}

Surveys and interviews conducted after the trip allowed us to measure the impact this opportunity had on learners, as well as the local community. The feedback received indicated that the work and learning opportunities experienced were highly valued. Many participants spoke of being able to address challenging situations within a safe and constructive space through trial and error. Community participants reported a strong level of trust and appreciation for the work completed, and extended invitations for future collaboration. A farewell ceremony and dinner celebrated the success of the three projects, as well as the relationships that had been built. (Figure 9 shows learners and children from the community at the farewell celebration.)

The impact of the field trip on learners included the development of a comprehensive understanding of the challenges involved in developing and designing viable water and sanitation projects in resource-poor environments. As the foundation for community development and health, water security became a reality for these learners, rather than simply one of the United Nations Sustainable Development Goals.

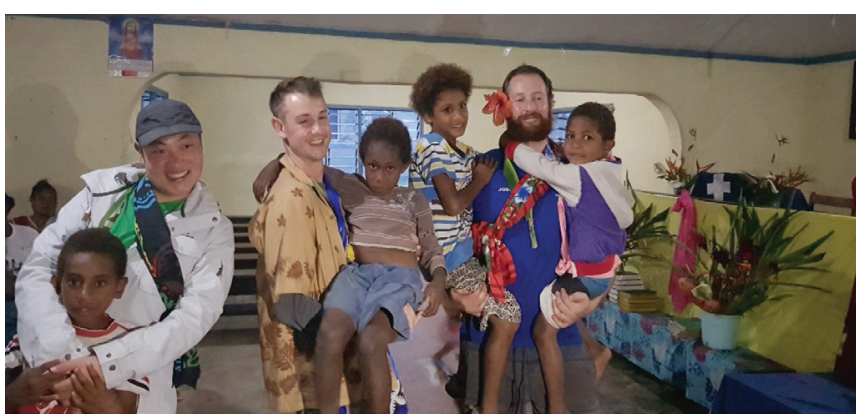

Figure 9. Farewell celebration for project members in Liro village. Source: Authors. 
For many of our learners, their future focus has now shifted to include water and sanitation work, as well as community development - a career path of which they had previously been unaware. A follow-up field trip involving Otago Polytechnic's Civil Engineering Department is planned for September 2019; this will continue the WASH projects in Liro and measure the effectiveness of the work done on the previous field trip.

In addition, a field trip involving third-year learners from the School of Nursing is being planned for 2020. Future opportunities to extend our activities to other Pacific Islands have been offered through collaboration with the Pacific community in Dunedin, and plans to evaluate an invitation to work in Fiji are also underway.

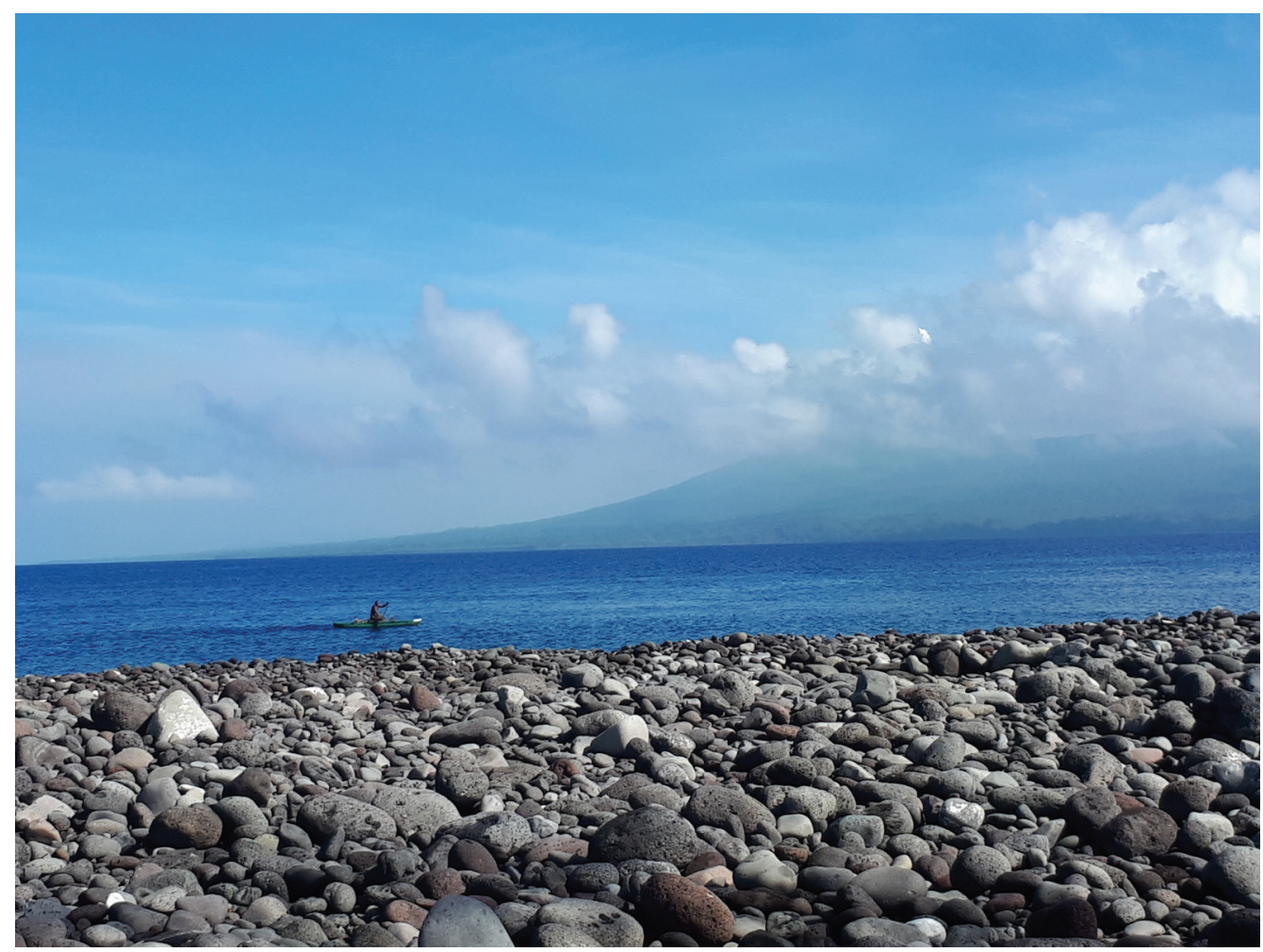

Figure 10. Local Paama fisherman.

Source: Authors.

\section{CONCLUSION}

As rural and isolated populations, Pacific islands face extreme challenges to health in relation to such factors as geographical location, climate change, natural disasters and access to services. In accordance with UN Sustainable Development Goal 6, "Clean Water and Sanitation," providing systems that achieve this outcome can have a major impact on Goal 3, "Good Health and Wellbeing." In a global community, there are opportunities for individuals to work towards equitable outcomes for all populations.

As an organisation, Otago Polytechnic strives to equip learners with the skills to practice in sustainable ways. This opportunity has allowed educators and learners alike to align practice with beliefs and seek out ways to effect change through inter-professional collaboration. 
Cynthia Mullens RN, BSN, MPH \& TM, PGCertHEd, Cert Mata a Ao Māori is a Senior Lecturer in the School of Nursing, Otago Polytechnic, Dunedin, New Zealand. Cindy obtained her Diploma of Nursing in Charlottesville, VA and worked within inpatient psychiatric facilities and the emergency department after graduating until 200 I. An opportunity to work in Relief and Development within Central and South America meant the next few years were spent traveling and working in a variety of resource poor environments. She obtained her Bachelor of Nursing through Flinders University in South Australia and worked extensively in Aboriginal Health in the Kimberley Region of Western Australia. Her Master of Public Health and Tropical Medicine from James Cook University underpins her focus on public health and firmly established her desire to work towards social and equitable health outcomes, both locally and globally.

Michael Mullens MSc, MEng(HydroWatRes), PGCE, BAM(Acct), HND Engineering, is a Senior Lecturer in the School of Engineering, Otago Polytechnic, Dunedin, New Zealand. Michael spent the first part of his career working in telecommunication engineering with companies such as AT\&T, Philips, Alcatel and Siemens. He has worked in senior management roles in Europe, the United States and Australasia. While working in Indonesia the need for sustainable development became much more of a reality which led to a career change to civil engineering, with a focus on water and sanitation. Relief and Development projects in Central and South America, Eastern Europe, South Pacific and India has given him focus to work towards social and equitable development both globally and locally. He received an HND in Electrical Engineering from Hatfield University, a Postgraduate Certificate in Telecommunications Management from Anglia University, a MSc of Satellite Engineering from Surrey University and a PGCE in Teaching from Surrey University. His civil engineering background includes a MSc of Hydrology and Water Resource Management from University South Australia and a MSc of Infrastructure Engineering and Management from Monash University and a Bachelor of Management (Accounting) from Otago Polytechnic.

Correspondence to: Michael Mullens, College of Engineering. Construction and Living Sciences, Otago Polytechnic, Private Bag 1910, Dunedin, New Zealand. Email: Michael.mullens@op.ac.nz

\section{REFERENCES}

Dillon, D. (2008). Rural contexts - islands. In Ross, J. (Ed.), Rural nursing: Aspects of Practice (pp. 19-30). Dunedin, NZ: Rural Health Opportunities.

Ross, J., Crawley, J., \& Mahoney, L. (20 17). Sustainable community development: Student nurses make a difference. Scope: Contemporary Research Topics: Learning and Teaching, 4, I-10.

World Health Organisation. (2019). Drinking-water (Fact sheet). Retrieved from https://www.who.int/news-room/fact-sheets/detail/drinking-water

United Nations, General Assembly (20I5). Transforming our world:The 2030 agenda for sustainable development (Resolution A RES/70/I). Retrieved from https://www.un.org/en/development/desa/population/migration/generalassembly/docs/globalcompact/A_RES_70_I_E.pdf 